INTERNATIONAL JOURNAL OF

ORGANIZATIONAL LEADERSHIP

WWW.CIKD.CA

\title{
The Role of Ego Depletion and Autonomy in the Relationship Between Time-pressure and Knowledge-based Behavior
}

\author{
Roksana Binte Rezwan ${ }^{1 *}$, Yoshi Takahashi ${ }^{2}$, Nu Nu Mai ${ }^{3}$
}

${ }^{1}$ Graduate School for International Development and Cooperation, Hiroshima University, Higashihiroshima, Japan

${ }^{2}$ Graduate School of Humanities and Social Sciences, Hiroshima University, Higashihiroshima, Japan

${ }^{3}$ Department of Management Studies, Yangon University of Economics, Yangon, Myanmar

\begin{tabular}{|c|c|}
\hline & BSTRACT \\
\hline $\begin{array}{l}\text { Keywords: } \\
\text { Ego depletion, Diary study, } \\
\text { Autonomy, Knowledge hiding, } \\
\text { Knowledge sharing }\end{array}$ & $\begin{array}{l}\text { This research explored the mechanisms by which time-pressure may influence different } \\
\text { knowledge-based behavior, e.g., knowledge sharing and knowledge hiding. Based on the strength } \\
\text { model of self-control, we proposed that ego depletion may explain why time-pressure may } \\
\text { decrease knowledge sharing and increase knowledge hiding. Moreover, based on the job demand- }\end{array}$ \\
\hline Received & between time-pressure and ego depletion. To test our hypotheses, we conducted a daily diary study \\
\hline 18 April 2021 & over ten workdays. We recruited 24 employees from a post-graduate class in a university in \\
\hline Received in revised form & $\begin{array}{l}\text { Myanmar to participate in our study and made } 153 \text { observations. We found that time-pressure was } \\
\text { associated with increased ego depletion. We also found a positively but marginally significant }\end{array}$ \\
\hline Accepted & association between time-pressure and evasive knowledge hiding and playing dumb knowledge \\
\hline 11 May 2021 & hiding. A small negative mediation effect of ego depletion was found on the relationship between \\
\hline $\begin{array}{l}\text { *Correspondence: } \\
\text { yhn780@hotmail.com }\end{array}$ & $\begin{array}{l}\text { autonomy on the relationship between time-pressure and ego depletion. This study contributes to } \\
\text { extant research by exploring for the first time the underlying mechanisms by which time-pressure } \\
\text { influences knowledge sharing and clarifying the mixed results found in previous studies of the } \\
\text { relationship between time-pressure and knowledge hiding. }\end{array}$ \\
\hline
\end{tabular}

(C)CIKD Publishing

Due to the significance of knowledge in creating competitive advantages (Nonaka, 1994), researchers and organization leaders have emphasized the importance of enhancing the knowledge-based behavior 
of employees (Wang \& Noe, 2010). However, in the current dynamic business era, companies face fierce competition. Efforts to maintain competitive advantages have led workplaces to become a source of constant pressure and stress. One consistent form of work pressure employees face is time constraints that affect knowledge-based behavior. However, few empirical studies (Connelly, Ford, Gallupe, Turel, \& Zweig, 2009; Connelly, Ford, Turel, Gallupe, \& Zweig, 2014; Škerlavaj, Connelly, Cerne, \& Dysvik, 2018) have focused on this issue.

In this study, we focused on knowledge-based behavior, namely knowledge sharing and knowledge hiding. Knowledge sharing has been investigated frequently due to its significance in tapping the potential of organizational knowledge and contributing to overall organizational learning. A Web of Science search using the term "knowledge sharing" returns more than 70,000 results. However, few empirical studies have considered the influence of time-pressure on the knowledge-sharing behavior of the employees of an organization (Asrar-ul-Haq \& Anwar, 2016; Wang \& Noe, 2010).

In contrast, Connelly, Zweig, Webster, and Trougakos (2012) introduced knowledge hiding as a separate concept from knowledge sharing, which occurs due to different kinds of focus (self vs. other) and motivation (anti-social vs. prosocial). Knowledge hiding is a counter-productive knowledge-based behavior considered a knowledge management failure (Wang, Han, Xiang, \& Hampson, 2018). Based on a review of 7,628 studies of knowledge management, Wang et al. (2018) suggested a lack of studies of knowledge-hiding behavior.

Connelly et al. (2014) found that time-pressure has a negative effect on knowledge sharing. However, the underlying mechanism by which time-pressure influences knowledge sharing was not explored. Further, mixed results regarding the influence of time-pressure on knowledge hiding, namely a positive significant relationship (Škerlavaj et al., 2018), or no significant relationship (Connelly et al., 2009) have been reported. It is unclear from the previous studies how time-pressure influences knowledge-sharing and knowledge-hiding behavior. Therefore, in this study, we focused on elucidating the mechanisms by which time-pressure may influence knowledge-sharing and knowledgehiding behavior.

Time constraints impose a greater need to expend more effort on a task, making the task more cognitively demanding (Kahneman, 2011). Cognitively demanding jobs require greater mental resources in terms of focus, self-control, and self-regulation to maintain or achieve improved performance. According to the strength model of self-control (Baumeister, Heatherton, \& Tice, 1994; Baumeister, Vohs, \& Tice, 2007), humans have limited mental resources which, when depleted, subsequently affect behavior in the short term. This phenomenon was termed ego depletion by Baumeister and colleagues. Carnevale and Fujita (2016) defined ego depletion as "a state of diminished 'strength' or reduced resources that results from an initial act of self-control, which hampers subsequent self-control efforts." Prem, Kubicek, Diestel, and Korunka (2016) found that time-pressure predicts ego depletion. Further, Kahneman (2011) suggested that "People who are cognitively busy are also more likely to make selfish choice” (p. 41). Mead, Baumeister, Gino, Schweitzer, and Ariely (2009) showed that ego-depleted participants tend to cheat more than non-depleted participants. When people are in a mental state that manifests as selfish behavior, prosocial behavior, such as knowledge sharing, might be less likely to occur. In contrast, knowledge hiding is also a selfish behavior that is focused on the benefit to the self. Therefore, based on the strength model of self-control (Baumeister 
et al., 1994; Baumeister et al., 2007), we hypothesized that the negative relationship between timepressure and knowledge sharing and the positive relationship between time-pressure and knowledgehiding behavior would be mediated by ego depletion.

This study further sought to understand how the positive influence of time-pressure on ego depletion can be buffered by job autonomy. According to the demand-control model (D-CM) (Karasek \& Theorell, 1990), the negative influence of high demand can be offset by high job control. Job autonomy is a form of job control that also acts as a job resource for employees (Buch, Dysvik, Kuvaas, \& Nerstad, 2015). Based on D-CM, we proposed that job autonomy would buffer the influence of timepressure on ego depletion and therefore enhance knowledge sharing and reduce knowledge hiding.

This study makes several contributions. First, this study contributes to the knowledge sharing and knowledge hiding literature by analyzing the influence of time-pressure through ego depletion. Second, this study examines the buffering effect of autonomy on the relationship between time-pressure and ego depletion. Third, this study responds to the call for research (Connelly, Černe, Dysvik, \& Škerlavaj, 2019) to explain employees' knowledge-based behavior utilizing the daily diary research design method. Further, this study provides practical insights for managers and leaders regarding how to design human resource management practices, particularly those that enhance job autonomy, reduce perceived time-pressure and, in turn, improve knowledge sharing and reduce knowledge-hiding behavior among employees.

\section{Theoretical Background and Hypotheses Development}

Knowledge sharing is the exchange of knowledge, ideas, and information with others, which may take place voluntarily or when requested. Conversely, knowledge hiding occurs when someone purposefully conceals knowledge when someone requests it. According to the definition of Connelly et al. (2012), there are three kinds of knowledge-hiding behavior. Evasive knowledge hiding is when someone provides false information, misguides, or explicitly deceives someone who requests knowledge. Second, playing dumb knowledge hiding occurs when someone acts as if he or she does not have the knowledge, even when he or she actually does. This also carries the intention of deceiving someone but perhaps to a lesser degree than in evasive knowledge hiding. Third, rationalized knowledge hiding is hiding knowledge from someone but while providing justification for doing so. This third form of hiding arguably carries the least intention to deceive.

Next, we explain how time-pressure may influence knowledge sharing and the different forms of knowledge hiding. Based on the strength model, we propose that one of the mechanisms by which time-pressure may influence knowledge-sharing and knowledge-hiding behavior is ego depletion. Additionally, based on the D-CM, we propose that providing job autonomy might be a solution to buffering the time-pressure-ego depletion relationship.

\section{Time-pressure and Knowledge-based Behavior}

Knowledge sharing is the prosocial act of providing one's knowledge, ideas, and information. An individual's knowledge can be a hard-earned asset, and such knowledge might also provide power and a competitive advantage. Therefore, as with any act of giving or charity, knowledge sharing involves a dilemma of choice since providing knowledge might be considered a loss. Instead of hoarding knowledge, the decision to share knowledge with others might be considered a social dilemma or moral 
judgment (Cabrera \& Cabrera, 2002). Therefore, the influence of time-pressure on knowledge sharing can be approached from two different perspectives: psychological and organizational.

There has been relatively less research on the influence of time-pressure on social dilemmas or prosocial behavior, or knowledge sharing. In psychology-based research on social dilemmas or moral judgments, a small number of studies have explored the influence of time-pressure through experimental manipulations (Capraro \& Cococcioni, 2016; Cone \& Rand, 2014; Suter \& Hertwig, 2011). However, these studies provided inconclusive results. Some suggested that high time-pressure leads individuals to act cooperatively (Cone \& Rand, 2014; Suter \& Hertwig, 2011); some suggested that extreme time-pressure leads individuals to act egoistically (Capraro \& Cococcioni, 2016), whereas others indicated no effect of time-pressure (Tinghög et al., 2016).

In contrast, among the few organization-based studies, Connelly et al. (2014) showed that timepressure decreases knowledge-sharing behavior. This is because, under time-pressure, employees prioritize the most important task at hand, thereby reducing knowledge-sharing behavior. In addition, Bjorvatn and Wald (2020) found that time-pressure is negatively associated with knowledge transfer effectiveness due to reduced trust among the team members. Therefore, from an organizational perspective, we hypothesize that:

H1: Time-pressure would have a negative association with knowledge sharing.

Knowledge hiding is an act of purposefully hiding what someone knows when another person requests the knowledge. In an experimental study, Škerlavaj et al. (2018) showed that time-pressure positively influences knowledge hiding. They explained that time and knowledge are both important resources. Therefore, given a resource-related crisis, employees feel the need to save another resource. However, in their study, the relationship between time-pressure and different types of knowledgehiding behavior was not explored. This leads to our second hypothesis:

H2: Time-pressure would have a positive association with knowledge hiding, that is, a) evasive knowledge hiding, b) playing dumb knowledge hiding, and c) rationalized knowledge hiding.

\section{Ego Depletion as a Mediator}

Time-pressure leads to the need to exert mental effort (Kahneman, 2011). According to the strength model of self-control, when an individual performs an activity that requires mental or cognitive effort, they utilize energy from a shared pool of resources, consisting of physical, mental, and psychological energy. Ego depletion represents a subjective appraisal of the energy available to oneself at a very low level, to the extent that exerting more effort is no longer desirable or pleasant (Baumeister, Heatherton, \& Tice, 1994; Baumeister, Vohs, \& Tice, 2007). We propose that since high time-pressure is an effortinducing context, it leads an individual into an ego-depleted state.

One reason why exerting mental effort under time-pressure may enhance ego depletion is related to self-control (Kahneman, 2011). Under time-pressure, individuals need to focus on tasks, avoiding any other distractions to the extent possible. However, self-control is not the only source of ego depletion. Any effortful activity might also lead to ego depletion (Francis \& Inzlicht, 2016). Prem et al. (2016) 
showed that another possible reason why time-pressure may increase ego depletion is anxiety. Therefore, our third hypothesis is:

H3: Time-pressure would have a positive association with ego depletion.

Francis and Inzlicht (2016) defined ego depletion as "a type of mental fatigue that occurs after engaging in any effortful, unrewarding task" (p. 720). In the current study, we explored ego depletion as one of the potential mechanisms by which time-pressure may influence knowledge-based behavior. When individuals feel a substantial amount of energy has been reduced by performing an effortinducing activity, such individuals enter a state of ego depletion (Baumeister, 2016). In an ego-depleted state, individuals want to avoid any further energy depletion. In the context of the strength model of self-control, many studies have shown that in ego-depleted states, an individual's self-control diminishes, which subsequently leads the individual to act in a self-serving manner (Capraro \& Cococcioni, 2016; Mead et al., 2009). Consistent with the strength model of self-control, we proposed that ego depletion would mediate the negative relationship between time-pressure and knowledge sharing. Further, the positive relationship between time-pressure and the three types of knowledge hiding might also be mediated by ego depletion. Moreover, evasive and playing dumb knowledge hiding are the most deceptive forms of knowledge hiding (Connelly et al., 2012). Therefore, it is possible that in an ego-depleted state, employees might have a stronger tendency to manifest evasive and playing dumb knowledge hiding than rationalized knowledge hiding. Therefore, we hypothesize that:

H4: Ego depletion would mediate the negative relationship between time-pressure and knowledge sharing.

Hs: Ego depletion would mediate the positive relationship between time-pressure and knowledge hiding, namely, a) evasive knowledge hiding, b) playing dumb knowledge hiding, and c) rationalized knowledge hiding.

\section{Autonomy as a Moderator}

Job autonomy is a job characteristic (Hackman \& Oldham, 1976) that refers to the degree of freedom employees have in the workplace regarding how independently they can conduct their work and the extent to which they have decision-making authority (Morgeson \& Humphrey, 2006). Studies have found that high job autonomy is associated with autonomous motivations, namely, intrinsic motivation (Foss, Minbaeva, \& Reinholt, 2009; Gagné et al., 2019). Francis and Inzlicht (2016) proposed that "have to" types of activities are more ego-depleting than "want to" types of activities. Job autonomy empowers employees by affording them more control and freedom, whereby employees can work more autonomously and therefore more willingly, rather than due to the feeling of "have to."

According to the D-CM, two dimensions of the work environment are psychological job demand and job control. Time-pressure is one kind of psychological job demand. Conversely, autonomy can be considered a form of job control. Whereas high demand places employees under stress and affects psychological well-being, high control can counteract the negative effect of high demand and restore well-being (Karasek \& Theorell, 1990). 
In the context of ego depletion, autonomy is considered a buffer against the negative effects of a stressful situation (Loschelder \& Friese, 2016). When effort is exerted willingly (high autonomy), ego depletion is lower than when the effort is exerted less willingly (low autonomy condition; Muraven, Rosman, \& Gagné, 2007; Muraven, Gagné, \& Rosman, 2008).

Muraven et al. (2008) manipulated different levels of self-control between two randomly assigned groups as their temptation to resist eating cookies (high self-control condition) or radish (low selfcontrol condition). The experimenters also randomly assigned participants to autonomous and nonautonomous conditions, defined as how they were instructed not to eat the food presented in front of them. The autonomous condition weakened the positive influence of their self-control on ego depletion. Similarly, based on the D-CM, we propose that job autonomy would moderate the relationship between time-pressure and ego depletion in a work context. The moderating effect would be that under high job autonomy, time-pressure would positively influence the employees' ego depletion but less strongly than how time-pressure would influence it under low job autonomy. Therefore, we hypothesize that:

H6: Job autonomy would moderate the relationship between time-pressure and ego depletion. Specifically, high job autonomy would diminish the effect of time-pressure on ego depletion.

The overall research framework of this study is presented in Figure.

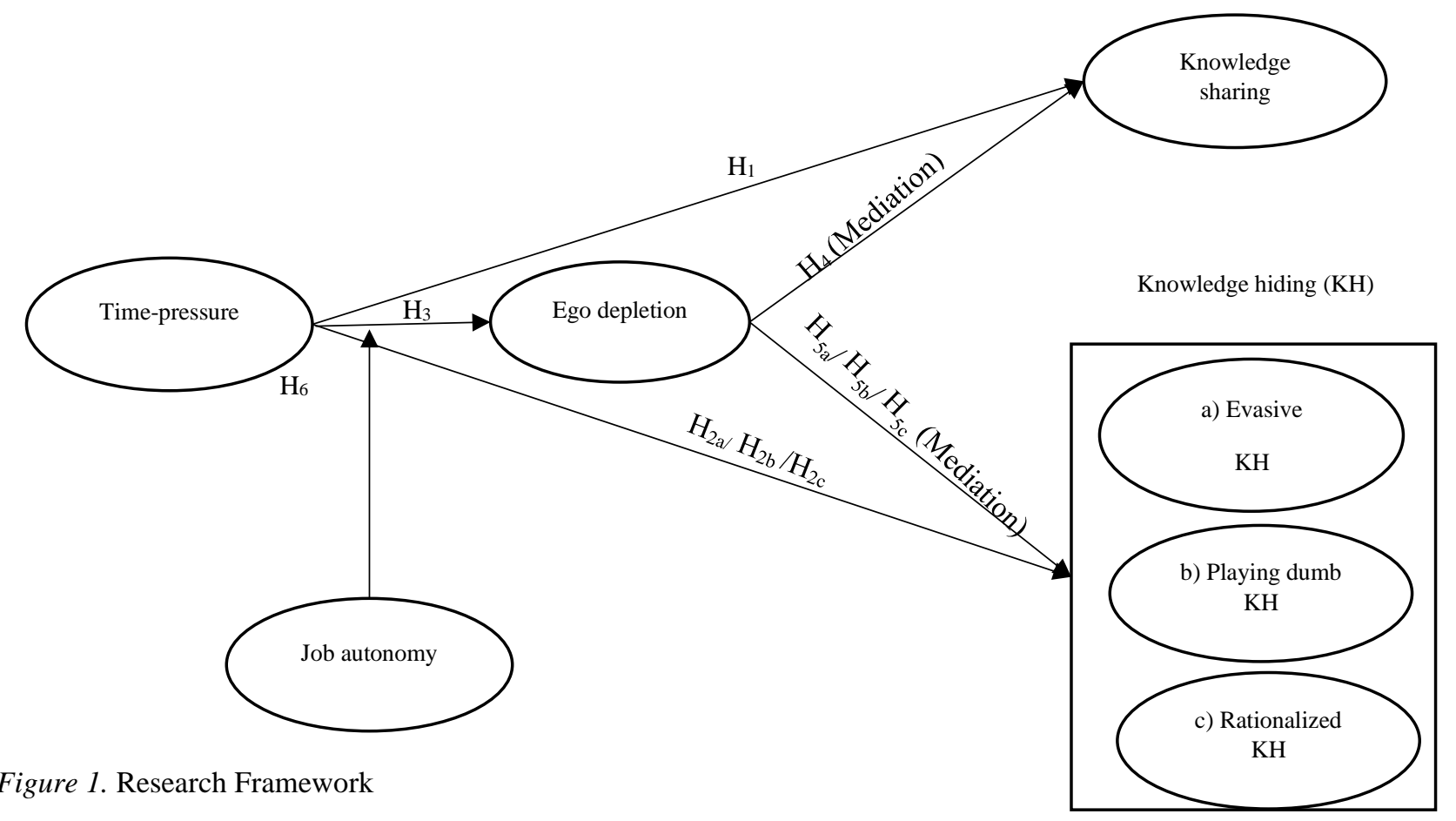

\section{Method}

\section{Participants and Procedure}

We conducted a daily diary study of employees over a period of 10 consecutive workdays. The participants were recruited from a post-graduate class at a university in Myanmar. We invited 80 students who are also currently working as full-time employees in different organizations in Myanmar 
to participate in our study. Twenty-seven individuals consented to take part in the study. We contacted these persons three days before conducting the main survey and collected initial data on betweenperson variables such as gender, age, job experience, type of job, and job autonomy in the current workplace. The institutional review board reviewed the research design, and permission was obtained to conduct the study.

We started the daily diary survey on the first workday of a workweek and continued the survey for 10 days, excluding weekends. We send a link to participate in the survey every working day at 16:00 with a subsequent reminder at 20:30 local time, given that the participants' working day would likely be complete at that time, allowing them to reflect on the day. Of the 27 participants, 24 provided answers to at least some of the surveys. On average, respondents provided reflections on 6.38 days.

\section{Measures}

Between-person variables. We measured the job autonomy of the participants before the beginning of the daily diary study. We utilized a nine-item scale adapted from Morgeson and Humphrey (2006). The internal consistency of the scale was $\alpha=.88$ and satisfactory. In addition, we collected information regarding the respondent's demographic characteristics, such as age, gender, their work industry, tenure, and total work experience. Demographic characteristics are provided in Table 1.

Table 1

Demographic Characteristics of the Respondents

\begin{tabular}{|c|c|c|}
\hline & Frequency & $\%$ \\
\hline \multicolumn{3}{|l|}{ Gender } \\
\hline Male & 7 & 29.2 \\
\hline Female & 1 & 70.8 \\
\hline \multicolumn{3}{|l|}{ Respondent's age (in years) } \\
\hline 20 to 24 & 1 & 4.1 \\
\hline 25 to 29 & 9 & 37.5 \\
\hline 30 to 34 & 6 & 25.0 \\
\hline 35 to 39 & 4 & 16.7 \\
\hline 40 to 44 & 1 & 4.2 \\
\hline 45 to 49 & 3 & 12.5 \\
\hline \multicolumn{3}{|l|}{ Organizational tenure (in years) } \\
\hline Less than 1 year & 2 & 8.3 \\
\hline $1-2$ years & 7 & 29.2 \\
\hline $3-4$ years & 5 & 20.8 \\
\hline $5-10$ years & 6 & 25.0 \\
\hline More than 10 years & 4 & 16.7 \\
\hline \multicolumn{3}{|l|}{ Total work experience (in years) } \\
\hline Less than 1 year & 0 & \\
\hline $1-2$ years & 3 & 12.5 \\
\hline $3-4$ years & 4 & 16.7 \\
\hline $5-10$ years & 10 & 41.7 \\
\hline More than 10 years & 7 & 29.2 \\
\hline \multicolumn{3}{|l|}{ Organization's sector of activity } \\
\hline Service & 12 & 50.0 \\
\hline Trading & 1 & 4.2 \\
\hline INGO & 1 & 4.2 \\
\hline NGO & 1 & 4.2 \\
\hline Manufacturing & 2 & 8.3 \\
\hline Pharmaceutical & 1 & 4.2 \\
\hline Power, Engineering Company & 1 & 4.2 \\
\hline Financial Sector & 1 & 4.2 \\
\hline Diversify business (Trading, Construction, etc) & 1 & 4.2 \\
\hline One of the biggest Local conglomerates & 1 & 4.2 \\
\hline Retail (Convenience Stores) & 1 & 4.2 \\
\hline Humanitarian Organization & 1 & 4.2 \\
\hline Total & 24 & 100.0 \\
\hline
\end{tabular}


Within-person variables. Following recommended practices for daily diary studies (Lanaj, Johnson, \& Barnes, 2014; Matta, Erol-Korkmaz, Johnson, \& Biçaksiz, 2014; Niks, de Jonge, Gevers, \& Houtman, 2017; Rodell \& Judge, 2009; Venz \& Shoshan, 2021), we utilized a short version of scales to measure daily time-pressure, daily ego depletion, daily knowledge sharing, and daily knowledge-hiding behavior. Ohly, Sonnentag, Niessen, and Zapf (2010) suggested that three-item scales are more appropriate to measure daily variables than scales with five or more items, to minimize respondent fatigue. We utilized three items adapted from Putrevu and Ratchford (1997) based on the highest factor loadings. We modified the scale by adding "Today at work" at the beginning of items to measure daily time-pressure at work. One example item is "Today at work, I found myself pressed for time." Respondents were asked to rate each item on a Likert scale ranging from 1 (strongly disagree) to 7 (strongly agree). To measure ego depletion, we utilized three items from Lindner, Lindner, and Retelsdorf (2019) based on the highest loading value. One example item is "Today at work I felt drained." Respondents rated each item on a scale ranging from 1 (not true) to 7 (very true). To measure daily knowledge-sharing behavior, a three-item scale was adopted from Swift and Virick (2013). One example item asked is "Today I frequently volunteered my knowledge to my coworkers." Respondents rated the items on a scale ranging from 1 (strongly disagree) to 7 (strongly agree). To measure daily knowledge hiding variables, we adopted three items each from Connelly et al. (2012) to assess evasive knowledge hiding, playing dumb, and rationalized hiding. Respondents rated the items on a scale ranging from 1 (strongly disagree) to 7 (strongly agree). We provided the following opening statement before asking about knowledge hiding: "Please think of the events that happened today, in which a coworker requested knowledge from you, and you declined to share your knowledge or expertise with him/her or did not give all of the information needed. In this specific situation I..."

To check the internal consistency of the within-person constructs' scale, we calculated Cronbach's $\alpha$ of the constructs for 10 days and computed an average (Nezlek, 2017). The average Cronbach's $\alpha$ values for the time-pressure, knowledge sharing, and ego depletion scales were 0.75 , 0.86 , and 0.53 , respectively. The average Cronbach's $\alpha$ values for the evasive knowledge hiding, playing dumb, and rationalized hiding scales were $0.76,0.80$, and 0.64 , respectively. In our daily diary study, we utilized shortened versions of the scales to minimize respondents' fatigue. It is important to note that "Holding inter-item correlations constant, alpha increases as the number of items increases" (Carmines \& Zeller, 1979, p. 46). Additionally, given the complexity of a withinperson study, Nezlek (2017) suggests that the standards for evaluating reliability might be more relaxed. Following the guidelines of Shrout (1988) that 0.41-0.60, 0.61-0.80, and 0.81-1.0 indicate fair, moderate, and substantial levels of reliability, respectively, the reliabilities of all the constructs in this study were between fair and substantial.

Because our study continued over a period of 10 days, we tried to minimize the expectancy bias associated with the order in which the questions were presented. Therefore, the constructs were presented in random order to the respondents. Moreover, the ordering of each statement within a construct was also randomized to avoid expectancy bias and primacy effect. 


\section{Analytic Strategy}

As we collected daily data for 10 days from the study participants, multiple days of data were nested within individuals. First, we conducted a null model analysis to compare an intercept-only model with a random intercept-only model varying among participants, via the lme4 package in $\mathrm{R}$ (Bates, Maechler, Bolker, \& Walker, 2015). We ran five models separately for knowledge sharing, evasive knowledge hiding, playing dumb knowledge hiding, rationalized knowledge hiding, and ego depletion. For all five models the random-intercept only model was significantly different from the intercept-only model. This confirmed that multilevel modeling analysis would be most appropriate for the daily diary data.

We conducted multilevel confirmatory factor analysis in Mplus 8.5 to confirm construct validity. Then, we followed the procedure recommended by Hayes and Rockwood (2020) to analyze multi-level data through multilevel conditional process analysis. We utilized the MLMED macro in SPSS by Rockwood and Hayes (2017) to conduct multilevel conditional process analyses. The details of the statistical procedure are outlined in Zhang, Zyphur, and Preacher (2009) and Hayes and Rockwood (2020). Due to the small sample size, we used a restricted maximum likelihood model (McNeish, 2017) and a random-intercept fixed-slope model (Venz \& Shoshan, 2021; Wehrt, Casper, \& Sonnentag, 2020), following previous studies and recommended practice.

In multilevel conditional process analyses, all within-individual variables were modeled at level 1 (time-pressure, ego depletion, evasive knowledge hiding, playing dumb knowledge hiding, rationalized knowledge hiding, and knowledge sharing), and the between-person cross-level moderator (job autonomy) and covariates (age, work experience) were modeled at level 2. In within-individual level analyses, all level 1 variables were person-mean centered (the person mean for a variable was subtracted from person-level daily data). Person-mean centering eliminates or adjusts for between-level fluctuations and helps identify within-person fluctuations. In the between-individual level analysis, the person-level means of the level 1 variables were utilized, along with the level 2 variables. Indirect effects were estimated by Monte Carlo simulation.

\section{Results}

We first calculated the mean and standard deviation of variables and within-individual level and between-individual level correlations between the variables. A summary of the descriptive statistics and correlations among variables is presented in Table 2. Next, we conducted multilevel confirmatory factor analysis with within-individual level latent variables (six factors: timepressure, ego depletion, knowledge sharing, evasive knowledge hiding, playing dumb knowledge hiding, and rationalized hiding). A six-factor model provided a better fit (root mean square error of approximation $(\mathrm{RMSEA})=.05$, comparative fit index $(\mathrm{CFI})=.93$, Tucker-Lewis index $(\mathrm{TLI})$ $=.91)$ than a one-factor model (RMSEA $=.17, \mathrm{CFI}=.18, \mathrm{TLI}=.06)$ or a four-factor model (timepressure, ego depletion, knowledge sharing, overall knowledge hiding: RMSEA $=.70, \mathrm{CFI}=.00$, $\mathrm{TLI}=.00$ ). This confirmed that a six-factor model was better than alternative models. Moreover, we also confirmed the intraclass correlation coefficient (ICC) of all items of the latent variables ranged from $19.4 \%$ to $74.1 \%$, which indicated that a substantial amount of variation in the daily- 
level data occurred at the individual level (level 2). This again confirmed the eligibility of the data for multilevel analyses.

Table 2

Means, Standard Deviations, and Correlations

\begin{tabular}{|c|c|c|c|c|c|c|c|c|c|}
\hline \multirow{2}{*}{\multicolumn{2}{|c|}{ Within-person variables }} & \multirow[t]{2}{*}{$M$} & \multirow[t]{2}{*}{$S D$} & \multicolumn{6}{|c|}{ Correlation } \\
\hline & & & & 1 & 2 & 3 & 4 & 5 & 6 \\
\hline 1 & Time-pressure & 3.80 & 1.56 & 1.00 & $.32^{* *}$ & .14 & $.22^{* *}$ & .12 & $-.17^{*}$ \\
\hline 2 & Ego depletion & 2.23 & 1.19 & $.23^{* *}$ & 1.00 & $.35^{* *}$ & $.55^{* *}$ & $.23^{* *}$ & $-.24^{* *}$ \\
\hline 3 & Evasive KH & 2.21 & 1.29 & .16 & $.23^{* *}$ & 1.00 & $.86^{* *}$ & $.78^{* *}$ & $-.34^{* *}$ \\
\hline 4 & Playing dumb KH & 2.61 & 1.45 & .12 & .12 & $.70^{* *}$ & 1.00 & $.77^{* *}$ & $-.42^{* *}$ \\
\hline 5 & Rationalized $\mathrm{KH}$ & 1.84 & 1.12 & $.20^{*}$ & $.32^{* *}$ & $.73^{* *}$ & $.66^{* *}$ & 1.00 & $-.22^{* *}$ \\
\hline 6 & Knowledge sharing & 4.70 & 1.37 & -.01 & $-.20^{*}$ & $-.23^{* *}$ & -.11 & $-.26^{* *}$ & 1.00 \\
\hline \multicolumn{10}{|c|}{ Between-person variables } \\
\hline 7 & Autonomy & 5.22 & 0.87 & -.08 & $-.42^{* *}$ & $-.37^{* *}$ & $-.35^{* *}$ & -.14 & $.45^{* *}$ \\
\hline 8 & Age & 3.03 & 1.32 & -.04 & -.12 & $.26^{* *}$ & -.11 & .03 & $-.27^{* *}$ \\
\hline 9 & Exp & 3.79 & 1.00 & $-.24^{* *}$ & -.14 & $-.28^{* *}$ & $-.46^{* *}$ & $-.36^{* *}$ & .16 \\
\hline
\end{tabular}

Note. To calculate the correlation between within-person variable daily level data has been utilized $\mathrm{n}=153$; Age was coded as $20-24=1,25-29=2$, $30-34=3,35-39=4,40-44=5 ; 45-49=6$. Exp (experience) was coded as Less than 1 years $=1 ; 1$ to 2 years $=2 ; 3$ to 5 years $=3 ; 6$ to 10 years $=4$, More than 10 years $=5$. The values below the diagonal for within-person variables represents correlation among the variables utilizing withinperson data $(\mathrm{n}=153)$. The value above the diagonal for within-person variable represents between-person correlation among the within-person variables $(\mathrm{n}=24)$. To calculate the correlation among between-person and within-person variables, the mean value of the person for a variable has been utilized $(\mathrm{n}=24) .{ }^{*} p<.05,{ }^{* *} p<.01, * * * p<.001$.

Next, we conducted multilevel conditional process analyses to test the hypotheses. The results are presented in Tables 3, 4, 5, and 6 for knowledge sharing, evasive knowledge hiding, playing dumb knowledge hiding, and rationalized knowledge hiding, respectively. First, we assessed a null model (M0) to calculate the intercept, utilizing the gls (generalized least square) function in $\mathrm{R}$ ( $\mathrm{n}$ =153). Next, we assessed a model (M1) predicting the intercept, which was allowed to vary among individuals. The M1 model for each outcome variable exhibited substantial within-person variance, as assessed through ICC (within-person variance/within-person variance + betweenperson variance), ranging from $27.5 \%$ to $53.0 \%$. Moreover, for all four outcome variables, M0 and M1 exhibited significantly different Chi-square values, as shown in all four tables. Next, we assessed three models each for our four outcome variables. Model 2 (M2) was a random intercept fixed-effect model without covariates, which calculated the mediation effect of ego depletion. Model 3 (M3) was a random intercept fixed-effect model with covariates, whereas model 4 (M4) estimated the moderation effect of job autonomy in a random intercept fixed-effect model with covariates. The strength of a daily diary study is that within-individual variances can be observed in the data. Since our hypotheses are more understandable when they are tested at the withinindividual level, within-individual level analyses are more appropriate for this research than between-individual level analyses. Therefore, although multilevel conditional process analyses can provide both within- and between-individual level effects, as shown in the tables, our focus was specifically on the within-individual level results.

Table 3 indicates a positive and significant influence of within-person time-pressure variance on knowledge-sharing behavior, which contradicted hypothesis $\mathrm{H}_{1}(B=.20, p=.01)$. 
Table 3

Hierarchical Linear Modeling Results for Knowledge-sharing Behavior

\begin{tabular}{|c|c|c|c|c|c|c|c|c|c|c|}
\hline \multirow[b]{3}{*}{ Fixed effect } & \multicolumn{2}{|c|}{ M0 } & \multicolumn{2}{|c|}{ M1 } & \multicolumn{2}{|c|}{ M2 } & \multicolumn{2}{|c|}{ M3 } & \multirow{2}{*}{\multicolumn{2}{|c|}{$\begin{array}{c}\text { M4 } \\
\text { Fixed effect } \\
\text { model with } \\
\text { covariate } \\
\text { (random } \\
\text { intercept) }\end{array}$}} \\
\hline & \multicolumn{2}{|c|}{$\begin{array}{l}\text { Intercept only } \\
\text { model }\end{array}$} & \multicolumn{2}{|c|}{$\begin{array}{c}\text { Random } \\
\text { intercept } \\
\text { only } \\
\text { model }\end{array}$} & \multicolumn{2}{|c|}{$\begin{array}{l}\text { Fixed effect model } \\
\text { without (random } \\
\text { intercept) }\end{array}$} & \multicolumn{2}{|c|}{$\begin{array}{l}\text { Fixed effect model } \\
\text { with covariate } \\
\text { (random intercept } \\
\text { only) }\end{array}$} & & \\
\hline & $B$ & $P$ & $B$ & $P$ & $B$ & $p$ & $B$ & $p$ & $B$ & $p$ \\
\hline Outcome: Ego depletion & & & & & & & & & & \\
\hline Within-person effect & & & & & & & & & & \\
\hline Constant & 2.23 & .00 & 2.26 & .00 & 1.51 & .01 & 1.53 & .09 & 4.32 & .40 \\
\hline Time-pressure $(\mathrm{H} 3, \mathrm{H} 4)$ & & & & & .17 & .05 & .17 & .05 & -1.23 & .03 \\
\hline Autonomy X Time-pressure (H6) & & & & & & & & & .26 & .01 \\
\hline Between-person effect & & & & & & & & & & \\
\hline Time-pressure & & & & & .19 & .14 & .20 & .15 & -.06 & .97 \\
\hline Autonomy & & & & & & & & & -.53 & .58 \\
\hline Autonomy X Time-pressure & & & & & & & & & .05 & .85 \\
\hline Age & & & & & & & -.04 & .80 & -.16 & .32 \\
\hline Exp & & & & & & & .02 & .92 & .12 & .53 \\
\hline Outcome: Knowledge sharing behavio & & & & & & & & & & \\
\hline Within-person effect & & & & & & & & & & \\
\hline Constant & 4.70 & .00 & 4.67 & .00 & 4.91 & .00 & 4.48 & .00 & 4.48 & .00 \\
\hline Time-pressure (Direct effect, H1) & & & & & .20 & .01 & .20 & .01 & .20 & .01 \\
\hline Ego depletion (H4) & & & & & -.20 & .02 & -.20 & .02 & -.20 & .02 \\
\hline Between-person effect & & & & & & & & & & \\
\hline $\begin{array}{l}\text { Time-pressure (Direct } \\
\text { effect) }\end{array}$ & & & & & .05 & .82 & .10 & .63 & .10 & .63 \\
\hline Ego depletion & & & & & -.20 & .52 & -.22 & .45 & -.22 & .45 \\
\hline Age & & & & & & & -.49 & .02 & -.49 & .02 \\
\hline Experience & & & & & & & .47 & .10 & .47 & .10 \\
\hline Random effect & & & & & & & & & & \\
\hline Level-1 residual estimates (variance) & & & & & & & & & & \\
\hline Ego depletion & & & 1.06 & .00 & 1.09 & .00 & 1.09 & .00 & 1.07 & .00 \\
\hline KSB & & & .99 & .00 & .89 & .00 & .89 & .00 & .89 & .00 \\
\hline Random effect estimates & & & & & & & & & & \\
\hline Ego depletion & & & .30 & .06 & .28 & .06 & .33 & .06 & .28 & .10 \\
\hline KSB & & & .89 & .01 & 1.10 & .01 & .90 & .01 & .90 & .01 \\
\hline Log likelihood & -262.90 & & -236.47 & & 926.7 & & 927.43 & & 922.62 & \\
\hline AIC & 529.80 & & 478.93 & & 934.80 & & 935.44 & & 930.62 & \\
\hline $\mathrm{BIC}$ & 535.84 & & 488.00 & & 949.50 & & 950.09 & & 945.23 & \\
\hline
\end{tabular}

The association between time-pressure and both evasive knowledge hiding $(B=.12, p=.06)$ and playing dumb $(B=.09, p=.09)$ was also found to be significant at a $90 \%$ confidence interval, as can be seen in Table 4 and Table 5, respectively. These results partially support $\mathrm{H}_{2 \mathrm{a}}$ and $\mathrm{H}_{2 b}$ on the positive relationship between time-pressure and evasive/playing dumb knowledge hiding. 
Table 4

Hierarchical Linear Modeling Results for Evasive Knowledge Hiding

\begin{tabular}{|c|c|c|c|c|c|c|c|c|c|c|}
\hline \multirow[b]{3}{*}{ Fixed effect } & \multirow{2}{*}{\multicolumn{2}{|c|}{$\begin{array}{c}\text { M0 } \\
\text { Intercept } \\
\text { only } \\
\text { model }\end{array}$}} & \multicolumn{2}{|c|}{ M1 } & \multicolumn{2}{|l|}{ M2 } & \multirow{2}{*}{\multicolumn{2}{|c|}{$\begin{array}{c}\text { M3 } \\
\text { Fixed effect } \\
\text { model with } \\
\text { covariate } \\
\text { (random } \\
\text { intercept only) }\end{array}$}} & \multirow{2}{*}{\multicolumn{2}{|c|}{$\begin{array}{c}\text { M4 } \\
\text { Fixed effect } \\
\text { model with } \\
\text { covariate } \\
\text { (random } \\
\text { intercept) } \\
\end{array}$}} \\
\hline & & & \multicolumn{2}{|c|}{$\begin{array}{c}\text { Random } \\
\text { intercept only } \\
\text { model }\end{array}$} & \multicolumn{2}{|c|}{$\begin{array}{l}\text { Fixed effect } \\
\text { model without } \\
\text { (random } \\
\text { intercept) }\end{array}$} & & & & \\
\hline & $B$ & $p$ & $B$ & $p$ & $B$ & $p$ & $B$ & $p$ & $B$ & $p$ \\
\hline \multicolumn{11}{|l|}{ Outcome: Ego depletion } \\
\hline \multicolumn{11}{|l|}{ Within-person effect } \\
\hline Constant & 2.23 & .00 & 2.26 & .00 & 1.511 & .01 & 1.53 & .09 & 4.32 & .40 \\
\hline Time-pressure (H3, H5a) & & & & & .17 & .05 & .17 & .05 & -1.23 & .03 \\
\hline Autonomy X Time-pressure (H6) & & & & & & & & & .26 & .01 \\
\hline \multicolumn{11}{|l|}{ Between-person effect } \\
\hline Time-pressure & & & & & .19 & .14 & .20 & .15 & -.06 & 0.97 \\
\hline Autonomy & & & & & & & & & -.53 & .58 \\
\hline Autonomy X Time-pressure & & & & & & & & & .05 & .85 \\
\hline Age & & & & & & & -.04 & .80 & -.16 & .32 \\
\hline Exp & & & & & & & .02 & .92 & .12 & .53 \\
\hline \multicolumn{11}{|l|}{ Outcome: Evasive KH } \\
\hline \multicolumn{11}{|l|}{ Within-person effect } \\
\hline Constant & 2.21 & .00 & 2.39 & .00 & .61 & .50 & 1.88 & .10 & 1.88 & .10 \\
\hline Time-pressure (Direct effect, H2a) & & & & & .12 & .06 & .12 & .06 & .12 & .06 \\
\hline Ego depletion (H5a) & & & & & .07 & .28 & .07 & .28 & .07 & .28 \\
\hline \multicolumn{11}{|l|}{ Between-person effect } \\
\hline Time-pressure (Direct effect) & & & & & .06 & .78 & -.02 & .93 & -.02 & .93 \\
\hline Ego depletion & & & & & .66 & .03 & .67 & .01 & .67 & .01 \\
\hline Age & & & & & & & .47 & .01 & .47 & .01 \\
\hline Experience & & & & & & & -.65 & .02 & -.65 & .02 \\
\hline \multicolumn{11}{|l|}{ Random effect } \\
\hline \multicolumn{11}{|l|}{ Level-1 residual estimates (variance) } \\
\hline Ego depletion & & & 1.11 & .00 & 1.09 & .00 & 1.09 & .00 & 1.05 & .00 \\
\hline Evasive $\mathrm{KH}$ & & & .60 & .00 & .58 & .00 & .58 & .00 & .58 & .00 \\
\hline \multicolumn{11}{|l|}{ Random effect estimates } \\
\hline Ego depletion & & & .30 & .06 & .28 & .06 & .33 & .06 & .28 & .10 \\
\hline Evasive KH & & & 1.21 & .00 & 1.07 & .00 & .73 & .01 & .73 & .01 \\
\hline Log likelihood & -251.76 & & -205.10 & & 870.18 & & 869.53 & & 864.71 & \\
\hline $\mathrm{AIC}$ & 507.52 & & 416.21 & & 878.18 & & 892.89 & & 872.71 & \\
\hline BIC & 513.56 & & 425.26 & & 892.89 & & 892.18 & & 887.32 & \\
\hline
\end{tabular}


Table 5

Hierarchical Linear Modeling Results for Playing Dumb Knowledge Hiding

\begin{tabular}{|c|c|c|c|c|c|c|c|c|c|c|}
\hline \multirow[b]{3}{*}{ Fixed effect } & \multicolumn{2}{|c|}{ M0 } & \multicolumn{2}{|c|}{ M1 } & \multicolumn{2}{|c|}{ M2 } & \multicolumn{2}{|c|}{$\mathrm{M} 3$} & \multicolumn{2}{|c|}{$\mathrm{M} 4$} \\
\hline & \multicolumn{2}{|c|}{$\begin{array}{l}\text { Intercept } \\
\text { only } \\
\text { model }\end{array}$} & \multicolumn{2}{|c|}{$\begin{array}{c}\text { Random } \\
\text { intercept only } \\
\text { model }\end{array}$} & \multicolumn{2}{|c|}{$\begin{array}{l}\text { Fixed effect } \\
\text { model without } \\
\text { (random } \\
\text { intercept) }\end{array}$} & \multicolumn{2}{|c|}{$\begin{array}{l}\text { Fixed effect } \\
\text { model with } \\
\text { covariate } \\
\text { (random } \\
\text { intercept only) }\end{array}$} & \multicolumn{2}{|c|}{$\begin{array}{c}\text { Fixed effect } \\
\text { model with } \\
\text { covariate } \\
\text { (random } \\
\text { intercept) }\end{array}$} \\
\hline & $B$ & $p$ & $B$ & $p$ & $B$ & $p$ & $B$ & $p$ & $\underline{B}$ & $p$ \\
\hline \multicolumn{11}{|l|}{ Outcome: Ego depletion } \\
\hline \multicolumn{11}{|l|}{ Within-person effect } \\
\hline Constant & 2.23 & .00 & 2.26 & .00 & 1.51 & .01 & 1.53 & .09 & 4.32 & .40 \\
\hline Time-pressure (H3, H5b) & & & & & .17 & .05 & .17 & .05 & -1.23 & .03 \\
\hline Autonomy X Time-pressure (H6) & & & & & & & & & .26 & .01 \\
\hline \multicolumn{11}{|l|}{ Between-person effect } \\
\hline Time-pressure & & & & & .19 & .14 & .20 & .15 & -.06 & .97 \\
\hline Autonomy & & & & & & & & & -.53 & .58 \\
\hline Autonomy X Time-pressure & & & & & & & & & .05 & .85 \\
\hline Age & & & & & & & -.04 & .80 & -.16 & .32 \\
\hline Exp & & & & & & & .02 & .92 & .12 & .53 \\
\hline \multicolumn{11}{|l|}{ Outcome: Playing dumb KH } \\
\hline \multicolumn{11}{|l|}{ Within-person effect } \\
\hline Constant & 1.84 & .00 & 2.37 & .00 & .22 & .74 & 1.55 & .09 & 1.55 & .09 \\
\hline Time-pressure (Direct effect, H2b) & & & & & .09 & .09 & .09 & .09 & .09 & .09 \\
\hline Ego depletion (H5b) & & & & & .04 & .45 & .04 & .46 & .04 & .46 \\
\hline \multicolumn{11}{|l|}{ Between-person effects } \\
\hline Time-pressure (Direct effect) & & & & & .02 & .90 & -.03 & .84 & -.03 & .84 \\
\hline Ego depletion & & & & & .72 & .00 & .74 & .00 & .74 & .00 \\
\hline Age & & & & & & & .19 & .19 & .19 & .19 \\
\hline Experience & & & & & & & -.47 & .02 & -.47 & .02 \\
\hline \multicolumn{11}{|l|}{ Random effect } \\
\hline \multicolumn{11}{|l|}{ Level-1 residual estimates (variance) } \\
\hline Ego depletion & & & .30 & .00 & 1.09 & .00 & 1.09 & .00 & 1.05 & .00 \\
\hline Playing dumb KH & & & .44 & .00 & .43 & .00 & .43 & .00 & .43 & .00 \\
\hline \multicolumn{11}{|l|}{ Random effect estimates } \\
\hline Ego depletion & & & 1.11 & .06 & .28 & .06 & .33 & .06 & .28 & .10 \\
\hline Playing dumb $\mathrm{KH}$ & & & .81 & .00 & 1.07 & .00 & .73 & .01 & .73 & .01 \\
\hline Log likelihood & -230.6 & & -168.60 & & 822.27 & & 824.84 & & 820.02 & \\
\hline AIC & 465.23 & & 343.20 & & 830.27 & & 832.84 & & 828.02 & \\
\hline $\mathrm{BIC}$ & 471.26 & & 352.25 & & 844.98 & & 847.49 & & 842.63 & \\
\hline
\end{tabular}

However, Table 6 shows that time-pressure had no significant direct association with rationalized knowledge hiding $(B=.07 ; p=.29)$. Therefore, $\mathrm{H}_{2 \mathrm{c}}$ was not supported. Time-pressure had a significant positive influence on ego depletion $(B=.17, p=.05)$ in model 2 and model 3 in all four analyses presented in Tables 3-6. Therefore, $\mathrm{H}_{3}$ was supported. Moreover, we also found a significant negative relationship between ego depletion and knowledge sharing $(B=-.20, p=$ $.02)$. Therefore, a small $(B=-.034)$ negative mediation effect of ego depletion was found, which supports $\mathrm{H}_{4}$. In contrast, ego depletion did not have any significant relationship with evasive $(B=$ $.07, p=.28)$, playing dumb $(B=.04, p=.45)$, or rationalized $(B=-.04, p=.53)$ knowledge hiding. We could not find any significant mediation effect of ego depletion on the relationships between time-pressure and different kinds of knowledge hiding, which failed to support $\mathrm{H}_{5 \mathrm{a}}, \mathrm{H}_{5 b}$, and $\mathrm{H}_{5 \mathrm{c}}$. Finally, job autonomy significantly moderated the relationship between time-pressure and ego depletion $(B=.26, p=.01)$. Job autonomy was found to strengthen the positive relationship between time-pressure and ego depletion. Even though the interaction effect found was significant, this is opposite to what we hypothesized in $\mathrm{H}_{6}$. Therefore, the results did not support $\mathrm{H}_{6}$. 
Table 6

Hierarchical Linear Modeling Results for Rationalized Knowledge Hiding

\begin{tabular}{|c|c|c|c|c|c|c|c|c|c|c|}
\hline \multirow[b]{3}{*}{ Fixed effect } & \multicolumn{3}{|c|}{ M0 } & \multirow[b]{2}{*}{$\begin{array}{c}\text { M1 } \\
\text { Random } \\
\text { intercept } \\
\text { only } \\
\text { model }\end{array}$} & \multicolumn{2}{|c|}{ M2 } & \multirow{2}{*}{\multicolumn{2}{|c|}{$\begin{array}{c}\text { M3 } \\
\text { Fixed effect } \\
\text { model with } \\
\text { covariate } \\
\text { (random } \\
\text { intercept only) }\end{array}$}} & \multirow{2}{*}{\multicolumn{2}{|c|}{$\begin{array}{c}\text { M4 } \\
\text { Fixed effect } \\
\text { model with } \\
\text { covariate } \\
\text { (random } \\
\text { intercept) }\end{array}$}} \\
\hline & \multicolumn{3}{|c|}{$\begin{array}{l}\text { Intercept only } \\
\text { model }\end{array}$} & & \multicolumn{2}{|c|}{$\begin{array}{l}\text { Fixed effect model } \\
\text { without (random } \\
\text { intercept) }\end{array}$} & & & & \\
\hline & $B$ & $p$ & $B$ & $p$ & $B$ & $p$ & $B$ & $p$ & $B$ & $p$ \\
\hline \multicolumn{11}{|l|}{ Outcome: Ego depletion } \\
\hline \multicolumn{11}{|l|}{ Within-person effect } \\
\hline Constant & 2.23 & .00 & 2.26 & .00 & 1.51 & .01 & 1.53 & .09 & 4.32 & .40 \\
\hline Time-pressure (H3, H5c) & & & & & .17 & 0.05 & .17 & .05 & -1.23 & .03 \\
\hline Autonomy X Time-pressure (H6) & & & & & & & & & .26 & .01 \\
\hline \multicolumn{11}{|l|}{ Between-person effect } \\
\hline Time-pressure & & & & & .19 & .14 & .20 & .15 & -.06 & .97 \\
\hline Autonomy & & & & & & & & & -.53 & .58 \\
\hline Autonomy X Time-pressure & & & & & & & & & .05 & .85 \\
\hline Age & & & & & & & -.04 & .80 & -.16 & .32 \\
\hline Exp & & & & & & & .02 & .92 & .12 & .53 \\
\hline \multicolumn{11}{|l|}{ Outcome: Rationalized KH } \\
\hline \multicolumn{11}{|l|}{ Within-person effect } \\
\hline Constant & 2.61 & .00 & 2.75 & .00 & 1.63 & .16 & 3.18 & .05 & 3.18 & .05 \\
\hline Time-pressure (Direct effect, $\mathbf{H 2 c}$ ) & & & & & .07 & .29 & .07 & .29 & .07 & .29 \\
\hline Ego depletion (H5c) & & & & & -.04 & .53 & -.04 & .53 & -.04 & .53 \\
\hline \multicolumn{11}{|l|}{ Between-person effect } \\
\hline Time-pressure (Direct effect) & & & & & .11 & .68 & .05 & .86 & .05 & .86 \\
\hline Ego depletion & & & & & .30 & .41 & .34 & .33 & .34 & .33 \\
\hline Age & & & & & & & .38 & .14 & .38 & .14 \\
\hline Experience & & & & & & & -.67 & .07 & -.67 & .07 \\
\hline \multicolumn{11}{|l|}{ Random effect } \\
\hline \multicolumn{11}{|l|}{ Level-1 residual estimates (variance) } \\
\hline Ego depletion & & & .30 & .00 & 1.09 & .00 & 1.09 & .00 & 1.05 & .00 \\
\hline Rationalized $\mathrm{KH}$ & & & .64 & .00 & .64 & .00 & .64 & .00 & .64 & .00 \\
\hline \multicolumn{11}{|l|}{ Random effect estimates } \\
\hline Ego depletion & & & 1.11 & .06 & .28 & .06 & .33 & .06 & .28 & .10 \\
\hline Rationalized KH & & & 1.67 & .00 & 1.81 & .00 & 1.64 & .01 & 1.64 & .01 \\
\hline Log likelihood & -270.23 & & -212.70 & & 894.32 & & 896.18 & & 891.36 & \\
\hline AIC & 544.46 & & 431.40 & & 902.32 & & 904.18 & & 899.36 & \\
\hline BIC & 550.50 & & 440.50 & & 917.03 & & 918.83 & & 913.97 & \\
\hline
\end{tabular}

\section{Discussion}

This study explored the mediation effect of ego depletion on the relationship between timepressure and knowledge-based behavior in the strength model of self-control. Further, based on the D-CM, this study also explored the moderation effect of job autonomy on the relationship between time-pressure and ego depletion. Our results can be discussed along with our two expected contributions as follows:

The first expected contribution of this study was the discovery of a mediation effect of ego depletion on the relationship between time-pressure and knowledge sharing and knowledge hiding. Based on the strength model of self-control, we found a significant positive influence of timepressure on ego depletion, consistent with our prediction. A negative mediation effect of ego depletion on the relationship between time-pressure and knowledge sharing was also identified. However, this negative mediation effect was relatively weak compared to the positive direct relationship between time-pressure and knowledge sharing. Therefore, the negative mediation effect of ego depletion on the relationship between time-pressure and knowledge sharing can be considered negligible. On the other hand, the mediation effect of ego depletion on the relationship 
between time-pressure and knowledge hiding could not be confirmed. Ego depletion did not show any significant relationship with evasive, playing dumb, or rationalized knowledge hiding. This result indicates that knowledge hiding does not happen due to a lack of employees' self-control resources in the ego-depleted state. Additional studies are needed to confirm the existence of such mediation effects.

In addition, we found a significant direct association between time-pressure and knowledge sharing, evasive knowledge hiding, and playing dumb knowledge hiding, which may suggest that unobserved mediators exist.

Contrary to our prediction that time-pressure would reduce knowledge-sharing behavior, timepressure increased knowledge-sharing behavior. Our results contradict those of Connelly et al. (2014), who found that time-pressure lowers employees' prosocial behavior. There could be several possible reasons underlying this positive relationship. Following previous studies (Adil \& Baig, 2018; Karasek, 1979), we conceptualized time-pressure as a job demand. However, Podsakoff, LePine, and LePine (2007) propose that there can be two kinds of job demands: demand stressors and challenge stressors. Unlike demand stressors, challenge stressors may influence the employees both positively and negatively. One possibility is that time-pressure could be a challenging stressor. Previous studies have found that challenging stressors such as time-pressure can negatively and positively affect the employees' well-being by enhancing their strain and positive attitude toward life (Widmer, Semmer, Kälin, Jacobshagen, \& Meier, 2012). Furthermore, Tooren and de Jong (2014) suggest that "time-pressure may not only be energy-depleting (like job insecurity), but also stimulating" (p. 115). Fay and Sonnentag (2002) showed that stressors like time-pressure are positively associated with proactive behavior. Knowledge sharing is a selfinitiated behavior. Therefore, it is possible that employees under time-pressure might be more motivated to initiate knowledge-sharing behavior.

In contrast, the association between time-pressure and both evasive knowledge hiding and playing dumb knowledge hiding was found to be marginally significant. These results may support our proposition that employees act in a self-serving manner under time constraints and deceitfully hide knowledge.

Unlike knowledge sharing, which happens proactively, knowledge hiding happens when the knowledgeable person receives a knowledge request. Therefore, it is possible that knowledge sharing may happen as a positive consequence (positive well-being), and knowledge hiding may happen as a negative consequence (strain) of a challenge stressor such as time-pressure.

Therefore, even though ego depletion was not found to be a significant mediator, there might be other potential mediators that justify the significance of the overall direct relationships. Timepressure may influence knowledge sharing positively through a positive attitude toward life (Widmer et al., 2012). Moreover, time-pressure may positively influence evasive knowledge hiding and playing dumb knowledge hiding through other factors such as negative affect, anxiety, and activation of heuristic (Capraro \& Cococcioni, 2016; Prem et al., 2016).

Moreover, the reason behind the insignificant result for rationalized hiding could be that theoretically rationalized hiding has less deceitful intentions, as proposed by Connelly et al. 
(2012). Under a time constraint, taking the strategy of hiding knowledge might be more timeconsuming. Therefore, time-pressure may not be associated with rationalized knowledge hiding.

The second expected contribution of this study is the identification of the moderation effect of job autonomy according to D-CM. Contrary to our expectation that job autonomy would have a negative moderation effect on the positive relationship between perceived time-pressure and ego depletion, we found a positive moderation. This result indicates that when employees with high job autonomy perceive high time-pressure, the positive relationship is strengthened. Väänänen, Toivanen, and Lallukka (2020) proposed that the role of job autonomy on employees' well-being is complicated. Job autonomy "can be both a resource and a burden" (p. 96). In organizations where the time frame is fragmented, and there is strong interdependency at work, having freedom and autonomy might add more complexity to work, affecting employees' well-being. As ego depletion did not mediate the relationships between time-pressure and knowledge-based behaviors, the significant moderation of job autonomy was not relevant to the scope of this study. Therefore, we should try to find other kinds of moderators in the future, particularly on direct relationships, so that we will be able to more generally identify the boundary conditions of the relationship between time-pressure and knowledge-based behavior.

\section{Conclusions}

This study confirms that time-pressure is associated with employees' ego depletion, which is expected, in turn, to relate to knowledge-based behaviors. Based on the strength model of selfcontrol theory, a small mediation effect of ego depletion was found between time-pressure and knowledge-sharing behavior. However, the mediation effect of ego depletion between timepressure and different kinds of knowledge hiding could not be confirmed. Furthermore, we found positive direct associations between time-pressure and knowledge sharing, evasive knowledge hiding, and playing dumb knowledge hiding. Time-pressure did not show any direct association with rationalized knowledge hiding. Finally, we found a positive significant moderation effect of job autonomy on the relationship between employees' perceived time-pressure and ego depletion.

This study has important implications for the leaders of organizations. Our study confirms that time-pressure is associated with evasive knowledge hiding and playing dumb knowledge hiding, although the mediation of ego depletion was not confirmed. Considering the negative consequences of employees' evasive knowledge hiding and playing dumb knowledge-hiding behavior in an organization, leaders should design jobs to minimize employees' time-pressure. In addition, leaders may also arrange training programs or sessions regarding managing the workflow to reduce the perceived time-pressure.

The results of this study should be considered carefully given the limitations. We conducted a longitudinal study, which is a relatively stronger design than a cross-sectional study. However, in our study, the number of observations was relatively small. Therefore, the results might have been subject to bias. Moreover, we collected daily data at only one point in time. Further studies are needed to confirm the results with large sample sizes and longitudinal research designs by collecting the data at several time points in a day. 


\section{References}

Adil, M. S., \& Baig, M. (2018). Impact of job demands-resources model on burnout and employee's well-being: Evidence from the pharmaceutical organisations of Karach. IIMB management review, 30, 119-133.

Asrar-ul-Haq, M., \& Anwar, S. (2016). A systematic review of knowledge management and knowledge sharing: Trends, issues, and challanges. Cogent Business \& Management, 3, 1127744.

Bates, D., Maechler, M., Bolker, B., \& Walker, S. (2015). Fitting linear mixed-effects models using lme4. Journal of Statistical Software, 67, 1-48.

Baumeister, R. F. (2016). Limited resources for self-regulation: A current overview of the strength model . In E. R. Hirt, J. J Clarkson, L. Jia (Eds.), Self-regulation and ego control? A conceptual analysis (pp. 44-78). London, England: Academic Press.

Baumeister, R. F., Heatherton, T., \& Tice, D. (1994). Losing control: How and why people fail at self-regulation. San Diego. CA: Academic Press.

Baumeister, R. F., Vohs, K. D., \& Tice, D. M. (2007). The strength model of self-control. Current Directions in Psychological Science, 16, 351-355.

Bjorvatn, T., \& Wald, A. (2020). The impact of time pressure on knowledge transfer effectiveness in teams: Trust as a critical but fragile mediator. Journal of Knowledge Management, 24, 2357-2372.

Buch, R., Dysvik, A., Kuvaas, B., \& Nerstad, C. G. (2015). It takes three to tango: Exploring the interplay among training intensity, job autonomy, and supervisor support in predicting knowledge sharing. Human Resource Management, 54, 623635 .

Cabrera, Á., \& Cabrera, E. F. (2002). Knowledge sharing dilemmas. Organization Studies, 23, 687-710.

Capraro, V., \& Cococcioni, G. (2016). Rethinking spontaneous giving: Extreme time pressure and ego-depletion favor selfregarding reactions. Scientific Reports, 6, 1-10.

Carmines, E. G., \& Zeller, R. A. (1979). Reliability and validity assessment. Newbury Park: Sage Pubications.

Carnevale, J., \& Fujita, K. (2016). What does ego depletion reveal about self-control? In Self-regulation and ego control? A conceptual analysis (pp. 87-108). London, England: Academic Press.

Cone, J., \& Rand, D. G. (2014). Time pressure increases cooperation in competitively framed social dilemmas. PLoS One, 9 , e115756.

Connelly, C. E., Černe, M., Dysvik, A., \& Škerlavaj, M. (2019). Understanding knowledge hiding in organizations. Journal of Organizational Behavior, 40, 779-782.

Connelly, C. E., Ford, D., Gallupe, B., Turel, O., \& D., Z. (2009). The effects of competition and time constraints on knowledge transfer: Exploratory findings from two experiments. Proceedings of 42nd Hawaii International Conference on System Sciences (HICSS-42) (pp. 1-10). Big Island, HI: IEEE.

Connelly, C. E, Ford, D., Turel, O., Gallupe, B., \& Zweig, D. (2014). 'I'm busy (and competitive)!' Antecedents of knowledge sharing under pressure. Knowledge Management Research \& Practice, 12, 74-85.

Connelly, C. E., Zweig, D., Webster, J., \& Trougakos, J. P. (2012). Knowledge hiding in organizations. Journal of Organizational Behavior, 33, 64-88.

Fay, D., \& Sonnentag, S. (2002). Rethinking the effects of stressors: A longitudinal study on personal initiative. Journal of Occupational Health Psychology, 7, 221-234.

Foss, N., Minbaeva, D., \& Reinholt, M. (2009). Encouraging knowledge sharing among employees: How job design matters. Human Resource Management, 48, 871-893.

Francis, Z., \& Inzlicht, M. (2016). Proximate and ultimate causes of ego depletion. In E. R. Hirt, J. J Clarkson, L. Jia (Eds.), SelfRegulation and Ego Control? A conceptual analysis (pp. 373-398). London, England: Academic Press. 
Gagné, M., Tian, A., Soo, C., Zhang, B., Ho, K., \& Hosszu, K. (2019). Different motivations for knowledge sharing and hiding: The role of motivating work design. Journal of Organizational Behavior, 40, 783-799.

Hackman, J. R., \& Oldham, G. R. (1976). Motivation through the design of work: Test of a theory. Organizational Behavior and Human Performance, 16, 250-279.

Hayes, A. F., \& Rockwood, N. J. (2020). Conditional process analysis: Concepts, computation, and advances in the modeling of the contingencies of mechanisms. American Behavioral Scientist, 64, 19-54.

Kahneman, D. (2011). Thinking, fast and slow. New York, NY: Farrar, Straus and Giroux.

Karasek Jr, R. A. (1979). Job demands, job decision latitude, and mental strain: Implications for job redesign. Administrative science quarterly, 24, 285-308.

Karasek, R., \& Theorell, T. (1990). Healthy work: Stress, productivity, and the reconstruction of working life. New York, NY: Basic Books.

Lanaj, K., Johnson, R. E., \& Barnes, C. M. (2014). Beginning the workday yet already depleted? Consequences of late-night smartphone use and sleep. Organizational Behavior and Human Decision Processes, 124, 11-23.

Lindner, C., Lindner, M. A., \& Retelsdorf, J. (2019). Measuring self-control depletion in achievement situations: A validation of the 5-item brief state self-control capacity scale. Diagnostica, 65, 228-242.

Loschelder, D., \& Friese, M. (2016). Moderators of the ego depletion effect. In E. R. Hirt, J. J Clarkson, L. Jia (Eds.), Selfregulation and ego control? A conceptual analysis (pp. 21-42). London, England: Avademic Press.

Matta, F. K., Erol-Korkmaz, H. T., Johnson, R. E., \& Biçaksiz, P. (2014). Significant work events and counterproductive work behavior: The role of fairness, emotions, and emotion regulation. Journal of Organizational Behavior, 35, 920-944.

McNeish, D. (2017). Small sample methods for multilevel modeling: A colloquial elucidation of REML and the Kenward-Roger correction. Multivariate Behavioral Research, 52(5), 661-670.

Mead, N. L., Baumeister, R. F., Gino, F., Schweitzer, M. E., \& Ariely, D. (2009). Too tired to tell the truth: Self-control resource depletion and dishonesty. Journal of Experimental Social Psychology, 45, 594-597.

Morgeson, F. P., \& Humphrey, S. E. (2006). The Work Design Questionnaire (WDQ): Developing and validating a comprehensive measure for assessing job design and the nature of work. Journal of Applied Psychology, 91, 1321-1339.

Muraven, M., Gagné, M., \& Rosman, H. (2008). Helpful self-control: Autonomy support, vitality, and depletion. Journal of Experimental Social Psychology, 44, 573-585.

Muraven, M., Rosman, H., \& Gagné, M. (2007). Lack of autonomy and self-control: Performance contingent rewards lead to greater depletion. Motivation and Emotion, 31, 322-330.

Nezlek, J. B. (2017). A practical guide to understanding reliability in studies of within-person variability. Journal of Research in Personality, 69, 149-155.

Niks, I. M., de Jonge, J., Gevers, J. M., \& Houtman, I. L. (2017). Divergent effects of detachment from work: A day-level study on employee creativity. European Journal of Work and Organizational Psychology, 26(2), 183-194.

Nonaka, I. (1994). A dynamic theory of organizational knowledge crreation. Organizational Science, 5, 14-37.

Ohly, S., Sonnentag, S., Niessen, C., \& Zapf, D. (2010). Diary studies in organizational research. Journal of Personnel Psychology, 9, 79-93.

Podsakoff, N. P., LePine, J. A., \& LePine, M. A. (2007). Differential challenge stressor-hindrance stressor relationships with job attitudes, turnover intentions, turnover, and withdrawal behavior: a meta-analysis. Journal of applied psychology, 92, 438454.

Prem, R., Kubicek, B., Diestel, S., \& Korunka, C. (2016). Regulatory job stressors and their within-person relationships with ego depletion: The roles of state anxiety, self-control effort, and job autonomy. Journal of Vocational Behavior, 92, 22-32.

Putrevu, S., \& Ratchford, B. T. (1997). A model of search behavior with an application to grocery shopping. Journal of Retailing, 73(4), 463-486. 
Rockwood, N. J., \& Hayes, A. F. (2017). MLmed: An SPSS macro for multilevel mediation and conditional process analysis. Poster presented at the annual meeting of the Association of Psychological Science (APS). Boston, MA.

Rodell, J. B., \& Judge, T. A. (2009). Can "good" stressors spark "bad" behaviors? The mediating role of emotions in links of challenge and hindrance stressors with citizenship and counterproductive behaviors. Journal of Applied Psychology, 94(6), $1438-1451$.

Shrout, P. E. (1998). Measurement reliability and agreement in psychiatry. Statistical Methods in Medical Research, 7, $301-317$.

Škerlavaj, M., Connelly, C. E., Cerne, M., \& Dysvik, A. (2018). Tell me if you can: Time pressure, prosocial motivation, perspective taking, and knowledge hiding. Journal of Knowledge Management, 22, 1489-1509.

Suter, R. S., \& Hertwig, R. (2011). Time and moral judgment. Cognition, 119, 454-458.

Swift, M., \& Virick, M. (2013). Perceived support, knowledge tacitness, and provider knowledge. Group \& Organization Management, 38, 717-742.

Tinghög, G., Andersson, D., Bonn, C., Johannesson, M., Kirchler, M., Koppel, L., \& Västfjäll, D. (2016). Intuition and moral decision-making: The effect of time pressure and cognitive load on moral judgment and altruistic behavior. PloS one, 11, $\mathrm{e} 0164012$

Tooren, v. d., \& de Jong, J. (2014). Job demands-resources and employee health and well-being. Career Development International, 19, 101-122.

Venz, L., \& Shoshan, H. N. (2021). Be smart, play dumb? A transactional perspective on day-specific knowledge hiding, interpersonal conflict, and psychological strain. Human Relations. Advance online publication. https://doi.org/10.1177/0018726721990438

Väänänen, A., Toivanen, M., \& Lallukka, T. (2020). Lost in Autonomy-Temporal Structures and Their Implications for Employees’ Autonomy and Well-Being among Knowledge Workers. Occupational Health Science, 4, 83-101.

Wang, S., \& Noe, R. A. (2010). Knowledge sharing: A review and directions for future research. Human Resource Management Review, 115-131.

Wang, Y., Han, M., Xiang, D., \& Hampson, D. (2018). The double-edged effects of perceived knowledge hiding: Empirical evidence from the sales context. Journal of Knowledge Management, 23, 279-296.

Wehrt, W., Casper, A., \& Sonnentag, S. (2020). Beyond depletion: Daily self-control motivation as an explanation of self-control failure at work. Journal of Organizational Behavior, 41, 931-947.

Widmer, P. S., Semmer, N. K., Kälin, W., Jacobshagen, N., \& Meier, L. L. (2012). The ambivalence of challenge stressors: Time pressure associated with both negative and positive well-being. Journal of Vocational Behavior, 80, 422-433.

Zhang, Z., Zyphur, M. J., \& Preacher, K. J. (2009). Testing multilevel mediation using hierarchical linear models problems and solutions. Organizational Research Methods, 12, 695-719. 